\title{
Equilibrium Study on Reactive Extraction of Nicotinic Acid from Aqueous Solution
}

\author{
Sushil Kumar, Suantak Kamsonlian, and Neha Chomal
}

\begin{abstract}
Nicotinic acid (3-pyridine carboxylic acid) widely used in food, pharmaceutical and biochemical industries is an important chemical. Due to ecological problems and complicate the synthesis methods, the chemical route for nicotinic acid production will become unattractive in the future. The aim of the present work is to study the reactive extraction of nicotinic acid from aqueous solutions using TOA dissolved in MIBK to intensify nicotinic acid production via enzymatic route. The extraction efficiency is determined in terms of distribution coefficient $\left(K_{\mathrm{D}}\right)$, degrees of extraction $(E)$ and loading ratios $(Z)$. The effects of initial acid concentration and composition of extractant (TOA) are determined. The maximum value of $K_{\mathrm{D}}$ is found to be 5.8 with TOA $(0.57 \mathrm{~mol} / \mathrm{L})$ at an acid concentration of $0.12 \mathrm{~mol} / \mathrm{L}$. The mathematical model, based on mass action law, is proposed to estimate the values of equilibrium constants $\left(K_{\mathrm{E}}\right)$ and number of reacting acid molecules per extractant molecules in chemical extraction. Population based search algorithm, differential evolution (DE) as an optimization algorithm is used to determine the equilibrium extraction constants $\left(K_{E}\right)$ and the stoichiometry of reactive extraction through a proposed equilibrium model. The model predicted values of $K_{\mathrm{E}}$ are showing good correlation with $R^{2}>0.98$ and maximum value of $S D=0.092$.
\end{abstract}

Index Terms-Differential evolution, equilibrium study, nicotinic acid, reactive extraction.

\section{INTRODUCTION}

Nicotinic acid (3-pyridine carboxylic acid) widely used in food, pharmaceutical and biochemical industries is an important chemical. Due to ecological problems and complicate the synthesis methods, the chemical route for nicotinic acid production will become unattractive in the future. The production of nicotinic acid and nicotinamide can be intensified by enzymatic conversion of 3cyanopyridine or biosynthesis [1]. This fermentation process, because of various impurities and very low concentration of product in the fermentation broth, requires an economic separation method to compete with the synthetic process. Among various available alternate processes for recovery of the product, a reactive extraction method has been proposed to be an effective primary separation step for the recovery of bio-products from a dilute fermentation process [2]. Long-chain aliphatic amines

Manuscript received March 28, 2014; revised May 15, 2014

Sushil Kumar is with the Department of Chemical Engineering, Motilal Nehru National Institute of Technology (MNNIT), Allahabad - 211004 (UP), India (e-mail: sushilk@mnnit.ac.in).

Suantak Kamsonlian was with the Department of Chemical Engineering, Motilal Nehru National Institute of Technology (MNNIT), Allahabad 211004 (UP), India.

Neha Chomal is with the Department of Chemical Engineering, Birla Institute of Technology and Science Pilani - 333 031, India. are found to effective extractants for the separation of carboxylic acids from dilute aqueous solution. Generally, these extractants are dissolved in a diluent such as ketone, alcohol, hydrocarbon, etc. to provide appropriate physical properties for use in the extraction process [2], [3]. Since the presence of carboxylic groups increases the solubility of acids in the aqueous phase, the strong interactions of solvent with solutes are necessary to extract carboxylic acids from dilute aqueous solutions. The diluents are categorized in two groups based on their activity: (i) inactive (inert) diluents, and (ii) active (polar) diluents. The presence of polar functional groups enables them to act as better solvation medium for the acid-extractant complex by the formation of hydrogen bond. Also, a polar diluent enhances the extracting power of non-polar extractant as compared to an inert diluent in the extraction of organic acids [4], [5]. The present work is aimed to find the equilibrium data with insight of mechanisms on the reactive extraction of nicotinic acid from aqueous solutions using TOA dissolved in MIBK.

\section{EXPERIMENTAL}

\section{A. Materials}

The materials used in this study are nicotinic acid with a purity of $99.5 \%$ (purchased from Himedia, India), tri-noctylamine (TOA) as an extractant with a purity of $98 \%$ (delivered by Fluka, USA) and methyl isobutyl ketone (MIBK) as a diluent with a purity of $99.8 \%$ (purchased from Spectrochem. Pvt. Ltd., India). Sodium hydroxide (CAS No.: 1310-73-2) used for titration is of analytical grade (98 mass $\%$ or 0.98 mass fraction) and was supplied by Merck Pvt. Ltd., Germany. The aqueous solutions of nicotinic acid are prepared in the concentration range of $0.02-0.12 \mathrm{~mol} / \mathrm{L}$ using distilled water. Organic solutions are prepared by varying the concentration of TOA $(0.23$ and $1.38 \mathrm{~mol} / \mathrm{L})$ in MIBK.

\section{B. Procedure}

The extraction equilibrium experiments are carried out at constant temperature $(298 \mathrm{~K})$ with equal volumes $(20 \mathrm{~mL}$ of each phase) of the aqueous and organic solutions shaken at $100 \mathrm{rpm}$ for 8 hours in conical flasks of $100 \mathrm{~mL}$ on a temperature controlled reciprocal shaker bath (HS 250 basic REMI labs). After attaining equilibrium, both the phases get settled for $2 \mathrm{hrs}$ in separating funnels of $125 \mathrm{~mL}$ at constant temperature $(298 \mathrm{~K})$ and atmospheric pressure. After settling, organic and aqueous phases are separated. The concentration of acid in the aqueous phase is determined using an UV spectrophotometer (Systronics, 119 model, $262 \mathrm{~nm})$. The acid concentration in the organic phase is 
calculated by mass balance. The equilibrium $\mathrm{pH}$ values of aqueous solutions are measured using a digital $\mathrm{pH}$-meter of Arm-Field Instruments (PCT 40, Basic Process Module). The reproducibility is checked by carrying out the experiments twice in some selected cases. The results are found to be reproducible within $\pm 5 \%$.

\section{Analysis}

The experimental data are analyzed by calculating distribution coefficient $\left(K_{D}=\overline{\mathrm{C}}_{\mathrm{HC}} / \mathrm{C}_{\mathrm{HC}}\right)$, degrees of extraction $\left[E=K_{\mathrm{D}} /\left(1+K_{\mathrm{D}}\right)\right]$ and loading ratio ( $Z=\overline{\mathrm{C}}_{\mathrm{HC}} /\left[\overline{\mathrm{NR}}_{3}\right]_{\mathrm{o}}$ ). Where, $\bar{C}_{H C}$ and $C_{\mathrm{HC}}$ are the total nicotinic acid concentration in the organic phase and in the aqueous phase, respectively, at equilibrium; and $\left[\overline{\mathrm{NR}}_{3}\right]_{0}$ is the initial TOA concentration in the organic phase.

\section{Theory}

The extraction mechanism of nicotinic acid (HNc) using tri-n-octylamine (TOA) as an extractant with various diluents is described by Eq. (1), showing interfacial equilibrium in the formation of complexes between acid and extractant::

$$
m \mathrm{HC}+n \overline{\mathrm{NR}_{3}} \Leftrightarrow \overline{\left(\mathrm{NR}_{3}\right)_{n}(\mathrm{HC})_{m}}
$$

The equilibrium constant $\left(K_{\mathrm{E}}\right)$ is calculated using Eq. (2)

$K_{\mathrm{E}}=\frac{\left[\overline{\left(\mathrm{NR}_{3}\right)_{n}(\mathrm{HC})_{m}}\right]}{\left[\mathrm{HC}^{m}\left[\overline{\mathrm{NR}_{3}}\right]^{n}\right.}=\frac{\left[\overline{\left(\mathrm{NR}_{3}\right)_{n}(\mathrm{HC})_{m}}\right]\left(1+K_{a} /\left[\mathrm{H}^{+}\right]\right)^{m}}{\left[\overline{\mathrm{NR}_{3}}\right]^{n} \mathrm{C}_{\mathrm{HC}}^{m}}$

The distribution coefficient $\left(K_{\mathrm{D}}\right)$ is defined as:

$$
K_{D}=\frac{\overline{\mathrm{C}}_{\mathrm{HC}}}{\mathrm{C}_{\mathrm{HC}}}=m \frac{\left[\overline{\left(\mathrm{NR}_{3}\right)_{n}(\mathrm{HC})_{m}}\right]}{\mathrm{C}_{\mathrm{HC}}}
$$

Substituting the values of $\left[\overline{\left(\mathrm{NR}_{3}\right)_{n}(\mathrm{HC})_{m}}\right]$ from Eq. (3) in Eq. (2) results Eq. (4).

$$
K_{E}=\frac{K_{D}\left(1+K_{a} /\left[\mathrm{H}^{+}\right]\right)^{m}}{m\left[\overline{\mathrm{NR}_{3}}\right]^{n} \mathrm{C}_{\mathrm{HC}}^{m-1}}
$$

The free extractant concentration, $\left[\overline{\mathrm{NR}_{3}}\right]$ in the organic phase, represented as:

$$
\begin{gathered}
{\left[\overline{\mathrm{NR}_{3}}\right]=\left[\overline{\mathrm{NR}_{3}}\right]_{i n}-n\left[\overline{\left(\mathrm{NR}_{3}\right)_{n}(\mathrm{HC})_{m}}\right]} \\
\Rightarrow\left[\overline{\mathrm{NR}_{3}}\right]=\left[\overline{\mathrm{NR}_{3}}\right]_{i n}-K_{D} n \mathrm{C}_{\mathrm{HC}} / m
\end{gathered}
$$

Using the Eqs. 4 and 6, Eq. 7 results in

$$
K_{D}=m K_{E}\left(\left[\overline{\mathrm{NR}_{3}}\right]_{i n}-K_{D} n \frac{\mathrm{C}_{\mathrm{HC}}}{m}\right)^{n} \frac{\mathrm{C}_{\mathrm{HC}}^{m-1}}{\left(1+K_{a} /\left[\mathrm{H}^{+}\right]\right)^{m}}
$$

The values of equilibrium extraction constant $\left(K_{\mathrm{E}}\right)$ and the number of reacting acid \& extractant molecules $(m \& n$ respectively) are estimated using Eq. (7).

The stoichiometry of the overall extraction equilibrium is dependent on the loading ratio in the organic phase, $Z$. If the organic phase is not highly concentrated by acid, i.e., at very low loading ratios $(Z<0.5), 1: 1$ complex of acid and extractant (TOA) is formed [6] [7]. A plot of $Z /(1-Z)$ versus $[H N c]$ yields a straight line with a slope of complexation constant $\left(K_{\mathrm{E} 1}\right)$ as given by Eq. (8):

$$
\frac{Z}{1-Z}=K_{E 1}[\mathrm{HNc}]
$$

The different model based on the assumption of simultaneously formation of various types of complexes $(m$, $n$ ) between acid and amine is presented. Based on the estimated values of $m$ per TOA molecule, the formation of different types of complexes, i.e., $(1,1)$ and $(2,1)$ are considered [8]. The stoichiometric equations describing the extraction are given by Eqs. (9 and 10):

$$
\begin{gathered}
\mathrm{HC}+\overline{\mathrm{NR}_{3}} \Leftrightarrow \overline{\mathrm{HCNR}_{3}} \\
\mathrm{HC}+\overline{\mathrm{HCNR}_{3}} \Leftrightarrow \overline{(\mathrm{HC})_{2} \mathrm{NR}_{3}}
\end{gathered}
$$

The corresponding extraction constants are calculated using Eqs. (11) - (12):

$$
\begin{gathered}
K_{11}=\frac{\left[\overline{\mathrm{HCNR}_{3}}\right]}{[\mathrm{HC}]\left[\overline{\mathrm{NR}_{3}}\right]}=\frac{\overline{\mathrm{C}}_{11}\left(1+K_{a} /\left[\mathrm{H}^{+}\right]\right)}{\mathrm{C}_{\mathrm{HC}} \mathrm{C}_{\mathrm{R}_{3} \mathrm{~N}}} \\
K_{21}=\frac{\left[\overline{(\mathrm{HC})_{2} \mathrm{NR}_{3}}\right]}{[\mathrm{HC}]\left[\overline{\mathrm{HCNR}_{3}}\right]}=\frac{\overline{\mathrm{C}}_{21}\left(1+K_{a} /\left[\mathrm{H}^{+}\right]\right)}{\mathrm{C}_{\mathrm{HC}} \overline{\mathrm{C}}_{11}}
\end{gathered}
$$

$\overline{\mathrm{C}}_{11}$ and $\overline{\mathrm{C}}_{21}$ are the concentrations of the complexes of $(1,1)$ and $(2,1)$, respectively. The acid concentration and free amine concentration in the organic phase are given by Eq. (13) and Eq. (14), respectively.

$$
\begin{aligned}
& \overline{\mathrm{C}}_{\mathrm{HC}}=\overline{\mathrm{C}}_{11}+2 \overline{\mathrm{C}}_{21}= \\
& K_{11} \mathrm{C}_{\mathrm{R}_{3} \mathrm{~N}} \mathrm{C}_{\mathrm{HC}} /\left(1+K_{a} /\left[\mathrm{H}^{+}\right]\right) \\
& +2 K_{21} \overline{\mathrm{C}}_{11} \mathrm{C}_{\mathrm{HC}} /\left(1+K_{a} /\left[\mathrm{H}^{+}\right]\right) \\
& \mathrm{C}_{\mathrm{R}_{3} \mathrm{~N}}=\mathrm{C}_{\mathrm{R}_{3} \mathrm{~N}_{\mathrm{in}}}-\left(\overline{\mathrm{C}}_{11}+\overline{\mathrm{C}}_{21}\right)= \\
& \mathrm{C}_{\mathrm{R}_{3} \mathrm{~N}_{\mathrm{in}}}-\left(K_{11} \mathrm{C}_{\mathrm{R}_{3} \mathrm{~N}} \mathrm{C}_{\mathrm{HC}} /\left(1+K_{a} /\left[\mathrm{H}^{+}\right]\right)\right. \\
& \left.+K_{21} \overline{\mathrm{C}}_{11} \mathrm{C}_{\mathrm{HC}} /\left(1+K_{a} /\left[\mathrm{H}^{+}\right]\right)\right)
\end{aligned}
$$

The values of the equilibrium constants $K_{11}$ and $K_{21}$ are estimated based on the total acid concentration in the aqueous phase at equilibrium, and by applying the mass action law (experimental results).

\section{RESUlTS AND DISCUSSION}

MIBK is active polar solvent with higher dipole moment, $\mu(2.79)$ and $E_{\mathrm{T}}(39.4)$ values. $E_{\mathrm{T}}$ parameter is an empirical 
parameter that should give assessment of solvation energy of the solute and is based on the absorption spectrum of pyridinium- $N$-phenolbetaine [9]. It provides anion solvation by ion-dipole and ion-induced dipole forces. A polar diluent increases the extracting ability of relatively low polar amines (TOA). This provides additional solvating power that allows higher levels of polar-amine complexes to stay in the organic phase. On the other hand, a non-polar diluent does not affect the extraction process with low polar amines (TOA). Due to this reason, MIBK is used as a diluent with TOA.

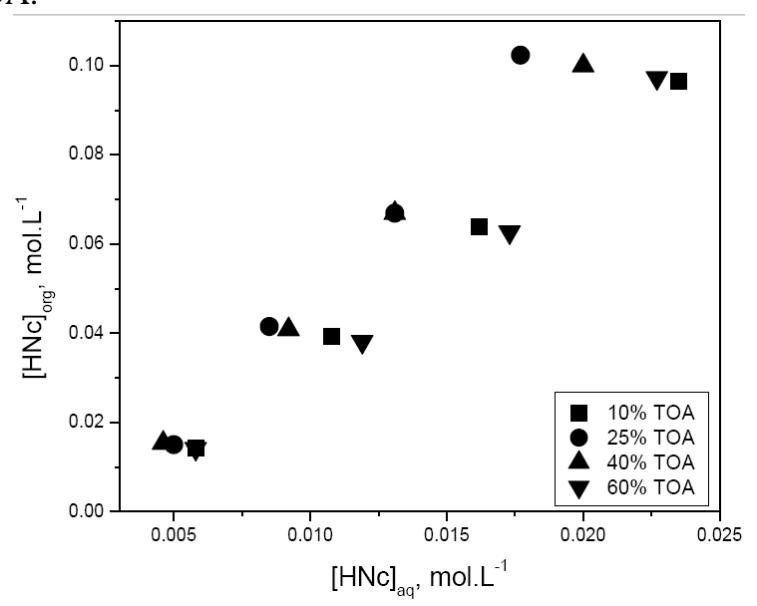

Fig. 1. Equilibrium isotherms of nicotinic acid for different concentrations of TOA dissolved in MIBK.

Equilibrium data are presented for the extraction of nicotinic acid using TOA in MIBK (Table I). The isotherms for nicotinic acid are determined from four aqueous solution concentrations and four concentrations of TOA as presented in Fig. 1. Almost linear relationship is found between acid concentration in both the phases (aqueous and organic phases) at equilibrium. This is due to Henry's law type isotherm valid for low acid concentration range. The highest strength of the complex solvation is found for MIBK with a maximum loading ratio $(Z=0.42)$ at highest acid concentration $(0.12 \mathrm{~mol} / \mathrm{L})$ and lowest amine concentration (0.23 mol/L). MIBK (oxygen bonded carbon based compound with electron acceptor capability and polarity) with non polar TOA is found to be good solvating agent for nicotinic acid-amine complexation. The distribution coefficients $\left(K_{\mathrm{D}}\right)$ and degree of extraction $(E)$ are found to initially increase, and then decrease with an increase in TOA concentration $(0.23-1.38 \mathrm{~mol} / \mathrm{L})$ at different concentrations of nicotinic acid $(0.02-0.12 \mathrm{~mol} / \mathrm{L})$. The concentration of acid may be the limiting factor for this trend of degree of extraction. Higher concentrations of TOA in diluents may have some interactions with diluents, which leads to decrease in the extraction efficiency. These trends of degree of extraction are also observed for the reactive extraction of acids by [10], [11]. Initial concentration of acid also affects the extraction efficiency as shown in Fig. 1. Since, low concentrations of nicotinic acid (0.02 to 0.12 $\mathrm{mol} / \mathrm{L})$ are used as compared to the concentrations of TOA $(0.23-1.38 \mathrm{~mol} / \mathrm{L})$, degree of extraction is found to be increase with an increase in acid concentration at different TOA concentrations (Fig. 1 and Table I).

TABLE I: EQUILIBRIUM RESULTS FOR THE EXTRACTION OF NICOTINIC ACID USING TOA DISSOLVED IN MIBK AT 298 K

\begin{tabular}{|c|c|c|c|c|c|c|c|c|}
\hline $\begin{array}{c}C_{\text {in }} \\
\mathrm{mol} / \mathrm{L}\end{array}$ & $\begin{array}{l}{\left[S_{\text {org }}\right]_{\text {in }}} \\
\mathbf{~ m o l} / \mathbf{L}\end{array}$ & $\begin{array}{c}C_{\mathrm{HNc}} \\
\mathrm{mol} / \mathbf{L}\end{array}$ & $\begin{array}{c}\overline{\mathrm{C}}_{\mathrm{HNc}} \\
\mathbf{m o l} / \mathbf{L}\end{array}$ & $K_{D}$ & $K_{D}^{\text {pred }}$ & $E$ & $Z$ & $p \mathbf{H}_{\mathrm{eq}}$ \\
\hline \multirow[t]{4}{*}{0.12} & 0.229 & 0.0235 & 0.0965 & 4.11 & 4.52 & 80.42 & 0.421 & 3.49 \\
\hline & 0.573 & 0.0177 & 0.1023 & 5.78 & 6.1 & 85.25 & 0.179 & 3.55 \\
\hline & 0.917 & 0.02 & 0.1 & 5 & 4.85 & 83.33 & 0.109 & 3.52 \\
\hline & 1.376 & 0.0227 & 0.0973 & 4.29 & 4.20 & 81.08 & 0.071 & 3.5 \\
\hline \multirow[t]{4}{*}{0.08} & 0.229 & 0.0162 & 0.0638 & 3.94 & 3.98 & 79.75 & 0.279 & 3.57 \\
\hline & 0.573 & 0.0131 & 0.0669 & 5.11 & 5.29 & 83.63 & 0.117 & 3.62 \\
\hline & 0.917 & 0.0131 & 0.0669 & 5.11 & 5.18 & 83.63 & 0.073 & 3.62 \\
\hline & 1.376 & 0.0173 & 0.0627 & 3.62 & 3.89 & 78.38 & 0.046 & 3.56 \\
\hline \multirow[t]{4}{*}{0.05} & 0.229 & 0.0108 & 0.0392 & 3.63 & 3.48 & 78.4 & 0.171 & 3.66 \\
\hline & 0.573 & 0.0085 & 0.0415 & 4.88 & 5.12 & 83 & 0.072 & 3.71 \\
\hline & 0.917 & 0.0092 & 0.0408 & 4.43 & 4.52 & 81.6 & 0.044 & 3.69 \\
\hline & 1.376 & 0.0119 & 0.0381 & 3.2 & 2.98 & 76.2 & 0.028 & 3.64 \\
\hline \multirow[t]{4}{*}{0.02} & 0.229 & 0.0058 & 0.0142 & 2.45 & 2.8 & 71 & 0.062 & 3.79 \\
\hline & 0.573 & 0.005 & 0.015 & 3 & 3.2 & 75 & 0.026 & 3.83 \\
\hline & 0.917 & 0.0046 & 0.0154 & 3.35 & 3.53 & 77 & 0.017 & 3.84 \\
\hline & 1.376 & 0.0058 & 0.0142 & 2.45 & 2.58 & 71 & 0.01 & 3.79 \\
\hline
\end{tabular}

The graphical method for determining of the number of extractant or acid molecules taking part in the formation of complexes is applicable, when only one type of complexes are formed. The model equation 7 is solved with experimental data to determine the values of equilibrium extraction constants $\left(K_{\mathrm{E}}\right)$, the number of acid molecule $(m)$ and reacting extractant molecules $(n)$ in the formation of acid:extractant complexes using optimization procedure. Most of the traditional optimization algorithms based on gradient methods have the possibility of getting trapped at local optimum depending upon the degree of non-linearity and initial guess [12]. A population based search algorithm called differential evolution (DE), which is simple and robust and has a proven successful record for various engineering applications in both single- and multi-objective optimization is employed [13], [14]. The key parameters of control in DE are: $N P$ - the population size, $C R$-the cross over constant, and $F$ the weight applied to random differential (scaling factor). Based on these heuristics, the values of DE key parameters for the present problem are set 
as $\mathrm{NP}=20 ; \mathrm{CR}=0.9 ; \mathrm{F}=0.5$. An objective function based on least square error between experimental data and predicted value of $K_{\mathrm{D}}$ has been minimized for the determination of overall equilibrium constants $\left(K_{\mathrm{E}}\right)$ and stoichiometry $(m \& n)$ of the reactions. For the estimation of simultaneous equilibrium extraction constants $\left(K_{11}\right.$ and $\left.K_{21}\right)$, an objective function based on least square error between experimental data and predicted value of $\bar{C}_{\mathrm{HC}}$ has been minimized.

The estimated values of stoichiometries of reactive extraction, overall equilibrium constants $\left(K_{\mathrm{E}}\right)$ and individual equilibrium constants $\left(K_{11}\right.$ and $\left.K_{21}\right)$ by this computational procedure are given in Table II. From the values of individual equilibrium constants $\left(K_{11}\right.$ and $\left.K_{21}\right)$, it is reflected that mostly 1:1 complexes between acid-TOA are formed. Equilibrium constants $\left(K_{\mathrm{E} 1}\right)$ with the assumption of 1:1 acid
- TOA complexes are also estimated from Eq. 8 and Fig. 2 and the values are comparable with $K_{11}$ as given in Table I. The predicted values of $K_{\mathrm{D}}$ and $Z$ for each concentration of TOA in MIBK using this equilibrium model (DE approach) are comparable with the experimental values of $K_{\mathrm{D}}$ as shown in Table I and Fig. 3. The predicted of $K_{\mathrm{D}}$ are showing little deviation from experimental values $K_{\mathrm{D}}$ at very lower acid concentration. When equilibrium extraction is carried out with very low concentration of acids, minor errors in the experimental concentration of aqueous phase may lead to high error in the experimental values of $K_{\mathrm{D}}$ ( $\bar{C}_{\mathrm{HC}} / \mathrm{C}_{\mathrm{HC}}$ ). It can be seen that the model values correctly represents the acid extraction using DE approach for predicting equilibrium parameters.

TABLE II: VALUES OF EQUILIBRIUM CONSTANTS AND STOICHIOMETRY OF REACTIONS

\begin{tabular}{|l|l|l|l|l|l|l|l|}
\hline $\begin{array}{l}\text { Acid conc. } \\
\mathbf{m o l} / \mathbf{L}\end{array}$ & $\begin{array}{l}\text { TOA conc. } \\
\mathbf{m o l} / \mathbf{L}\end{array}$ & $\boldsymbol{K}_{\mathbf{E}}$ & $\boldsymbol{m}$ & $\boldsymbol{n}$ & $\boldsymbol{K}_{\mathbf{1 1}}$ & $\boldsymbol{K}_{\mathbf{2 1}}$ & $\boldsymbol{K}_{\mathbf{E 1}}$ \\
\hline $0.02-0.12$ & 0.23 & 143.84 & 1.55 & 1 & 27.81 & 0.99 & 27.15 \\
\cline { 2 - 8 } & 0.57 & 65.73 & 1.50 & 1 & 11.61 & 1.00 & 11.30 \\
\cline { 2 - 8 } & 0.91 & 24.93 & 1.39 & 1 & 6.23 & 0.99 & 5.88 \\
\cline { 2 - 8 } & 1.38 & 8.54 & 1.33 & 1 & 3.11 & 0.99 & 3.05 \\
\hline
\end{tabular}

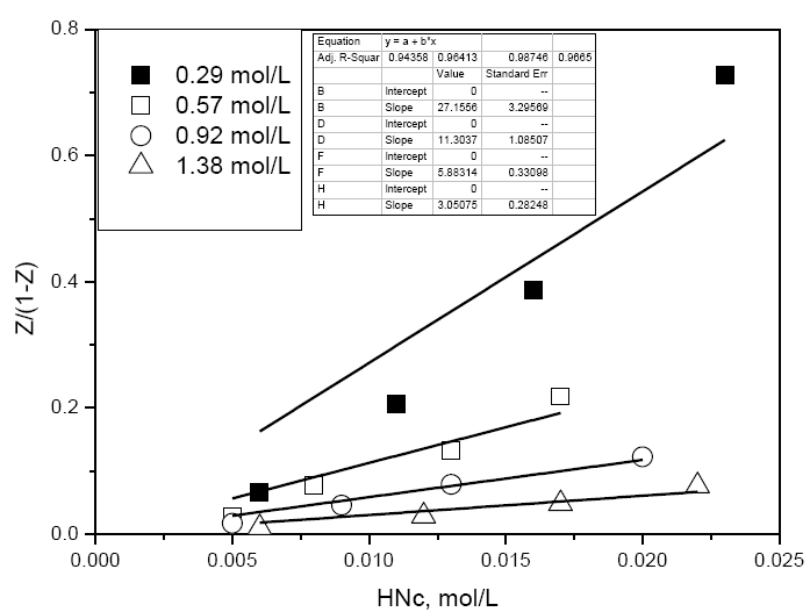

Fig. 2. Estimation of equilibrium constants for 1:1 complex of acid and TOA for different concentrations of TOA dissolved in MIBK.

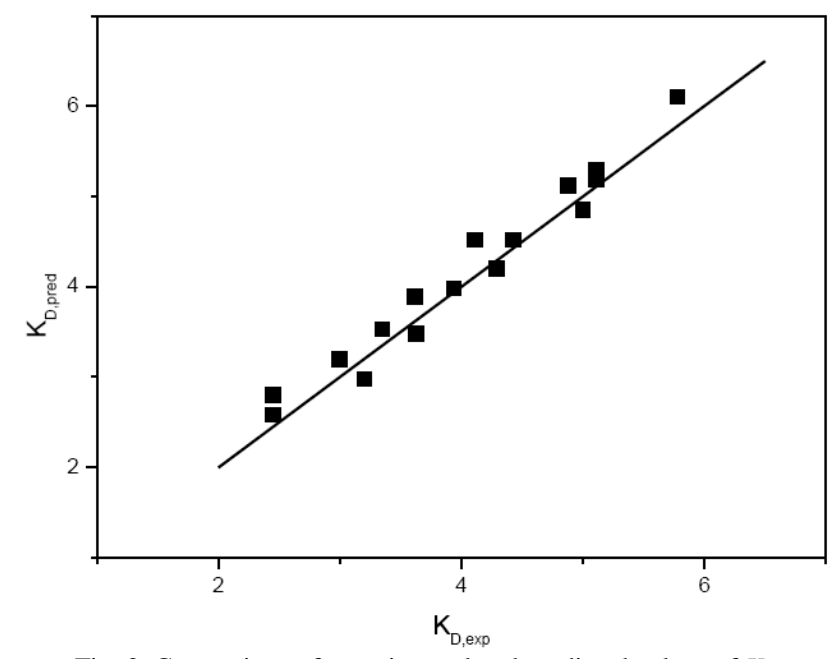

Fig. 3. Comparison of experimental and predicted values of $K_{\mathrm{D}}$.

\section{CONCLUSIONS}

The equilibrium reactive extraction of nicotinic acid is studied considering MIBK as a diluent with an amine based extractant, TOA at isothermal condition $(298 \pm 1 \mathrm{~K})$. The MIBK (aprotic or proton acceptor, $\mu=2.79, E_{\mathrm{T}}=39.4$ ) is an active (polar) diluent, which enhances the extractability of relatively non-polar extractant (TOA). The degree of extraction increases with an increase in acid concentration and TOA concentration. The maximum value of the $K_{\mathrm{D}}$ in the chemical extraction are found to be 5.80 with TOA $(0.57 \mathrm{~mol} / \mathrm{L})$ in MIBK for an acid concentration of 0.12 mol/L. The predicted values of $K_{\mathrm{D}}$ for each concentration of TOA in MIBK using this equilibrium model and DE approach are comparable with the experimental values of $K_{\mathrm{D}}$.

\section{ACKNOWLEDGEMENT}

Department of Science and Technology (DST), India, for funding a research project under Fast track scheme for Young Scientist, SR/FTP/ETA-25/2011, Reactive Extraction of Nicotinic- and Isonicotinic Acids from Aqueous Solution (PI: Dr. Sushil Kumar, MNNIT, Allhabad, India).

\section{REFERENCES}

[1] S. Kumar and B. V. Babu, "Process intensification of nicotinic acid production via enzymatic conversion using reactive extraction," Chem. Biochem. Eng. Q., vol. 23, no. 3, pp. 367-376, 2009.

[2] S. Kumar and B. V. Babu, "Process intensification for separation of carboxylic acids from fermentation broths using reactive extraction," J. Fut. Eng. Technol., vol. 3, pp. 19-25, 2008.

[3] A. S. Kertes and C. King, "Extraction chemistry of fermentation product carboxylic acids," Biotechnol. Bioeng. Vol. 28, pp. 269$282,1986$.

[4] D. Yankov, J. Molinier, J. Albet, G. Malmary, and G. Kyuchoukov, "Lactic acid extraction from aqueous solutions with tri-n-octylamine dissolved in decanol and dodecane," Biochem. Eng. J., vol. 21, pp. 63-71, 2004.

[5] M. Mariya, J. Albet, J. Molinier, and G. Kyuchoukov, "Specific influence of the modifier (1-decanol) on the extraction of tartaric acid by different extractants," Ind. Eng. Chem. Res., vol. 44, pp. 6534$6538,2005$. 
[6] K. L. Wasewar and V. G. Pangarkar, "Intensification of propionic acid production by reactive extraction: effect of diluents on equilibrium," Chem. Biochem. Eng. Q., vol. 20, pp. 235-240, 2006.

[7] S. Kumar and B. V. Babu, "Extraction of pyridine-3-carboxylic acid using 1-dioctylphosphoryloctane (TOPO) with different diluents: Equilibrium studies," J. Chem. Eng. Data., vol. 54, no. 9, pp. 26692677, 2009.

[8] S. Kumar, D. Datta, and B. V. Babu, "Experimental data and theoretical (Chemodel using DE approach and LSER model) predictions on reactive extraction of mono-Carboxylic acids using Tri-n-Octylamine," J. Chem. Eng. Data., vol. 55, pp. 4290-4300, 2010.

[9] Y. Marcus, "The Effectiveness of solvents as hydrogen bond donors," J. Sol. Chem., vol. 20, no. 9, pp. 929-944, 1991.

[10] A. Keshav, S. Chand and K. L. Wasewar, "Equilibrium studies for extraction of propionic acid using Tri- $n$-butyl phosphate in different Solvents," J. Chem. Eng. Data., vol. 53, pp. 1424-1430, 2008.

[11] S. Kumar and B. V. Babu, "Reactive extraction of nicotinic acid using Tri-n-octylamine (TOA) dissolved in different diluents," in Proc. 2010-Annual Meeting of AIChE, Salt Lake City, USA, 2010.

[12] B. V. Babu, Process plant simulation, Oxford University Press, India, 2004.

[13] B. V. Babu and R. Angira, "Modified differential evolution (MDE) for optimization of non-linear chemical processes," Comp. Chem. Eng., vol. 30, pp. 989-1002, 2006.

[14] S. Kumar, D. Datta, and B. V. Babu, "Estimation of equilibrium parameters using differential evolution in reactive extraction of propionic acid by tri-n-butyl phosphate," Chem. Eng. Processing, vol. 50, pp. 614-622, 2011

Sushil Kumar is currently an assistant professor in the Department of Chemical Engineering at Motilal Nehru National Institute of Technology (MNNIT), Allahabad has over 10 years of industrial, teaching, and research experience. Prior to MNNIT, Allahabad, he served as an assistant professor in Department of Chemical Engineering at BITS-Pilani, Pilani Campus. He also worked with Central Institute of Plastic Engineering and Technology (CIPET), Lucknow for one and half years as Technical Officer and Graduate Engineer Trainee. He did his B.Tech from Harcourt Butler Technological Institute (HBTI) - Kanpur, M Tech from Indian Institute of Technology (IIT) - Kanpur and PhD from BITS - Pilani.

His current research interests include Process Intensification, Polymer Science \& Technology, Biochemical Engineering, Green Technology, Chemical Thermodynamics, and Renewable Energy Sources. He has around 68 research publications (22 refereed journals, 48 conferences and 2 book chapters) to his credit which have been published over the years in various International and National Journals and Conference Proceedings. Dr Kumar guided one PhD in the area of Process Intensification (Reactive Extraction) and currently, he is supervising 3 scholars for their doctoral research. Besides this, he has guided $5 \mathrm{ME}$ Dissertations and around $20 \mathrm{BE}$ Project students under his supervision.

$\mathrm{He}$ is the referee and expert reviewer of 14 International Journals of repute (Journal of Chemical and Engineering Data, Industrial and Engineering Chemistry Research, Separation and Purification Technology, Fluid Phase Equilibria, Biotechnology and Bioprocess Engineering, Desalination etc.). He also reviewed three books of Tata McGraw Hill publisher. He is awarded Research Project by Department of Science and Technology (DST), New Delhi, India under Fast Track Scheme for Young Scientists, 2012-2014

Dr. Kumar is a life member of Indian Institute of Chemical Engineers (IIChE), Fellow member of International Congress of Chemistry and Environment (ICCE), member of AIChE for the year - 2010 to 2013, and Executive Committee Member, Lucknow Regional Centre of IIChE chapter. He organized a national conference on "Technological Advancements in Chemical and Environmental Engineering (TACEE 2012)" held at BITS-Pilani during March 23-24, 2012, and also worked as a Treasurer for SCHEMCON 2012 held during September 27-28, 2012 at BITS-Pilani. 